\title{
Investigation of Steel Lug Nut Failures with Brittle Fracture Characteristics
}

\author{
D.F. Susan, N.R. Sorensen, J.R. Michael, A.C. Kilgo, and G.L. Clark II \\ Sandia National Laboratories, Albuquerque, New Mexico
}

Tractor trailer dual wheel inner cap nuts failed periodically over several years. The cap nuts were specified as 10B21 steel, a low carbon steel with boron addition. For corrosion protection, the cap nuts were zinc plated and chromate coated. In this study, the microscopic characteristics of the cap nut fractures were investigated along with companion tensile testing, hardness measurement, and novel insitu fracture with Auger spectroscopy. The failure mechanism was brittle intergranular fracture due to hydrogen and/or temper embrittlement. Contributing causes for delayed cracking due to hydrogen could include the following: 1) inadequate $\mathrm{H}$ bakeout after plating, 2) higher strength steel (more susceptible to $\mathrm{H}$ embrittlement) with lower fracture toughness, 3) hydrogen from corrosion reactions due to inadequate $\mathrm{Zn}$ and chromate coverage, 4) higher $\mathrm{Cr}$ in the failed samples could make the material more susceptible to temper embrittlement, and 5) periodic re-torqueing of lug nuts also may contribute to cracking, essentially mimicking a delayed hydrogen cracking test.[1] Supporting evidence of "thumbnail" cracks, with more corrosion than other areas of the fractures, suggested pre-existing cracks induced during maintenance.

Scanning electron microscopy showed intergranular (IG) brittle fracture or mixed transgranular (cleavage)/IG fracture (Fig. 1). Intergranular fracture indicates embrittlement of normally ductile steel.[2] The cap nuts contain a tempered martensite microstructure and fracture occurs along prior austenite grain boundaries. Hydrogen embrittlement is known to be exacerbated in higher strength steels. Figure 2 displays Rockwell $\mathrm{C}$ hardness and tensile test results of cap nuts. The failed cap nuts reside in a higher strength regime, 37-40 $\mathrm{HRC}$, putting them at greater risk for $\mathrm{H}$ embrittlement.[2,3] All failures were traced to newer lots of material with higher strength from a new supplier. Older lots with hardness in the 33 - 35 HRC range exhibited more elongation and ductile fracture morphology.

Chemical analyses were performed by atomic emission spectroscopy and combustion analysis to determine the hydrogen concentration in old (good) and new (bad) sets of cap nuts. Hydrogen levels in the 2-3ppm range were found, Table 1, with no difference between good and bad lots, suggesting that this level of hydrogen is sufficient to cause embrittlement in samples that are also in the higher strength regime. $[3,4]$ Some chemistry differences were observed such as higher $\mathrm{Cr}$ and low $\mathrm{Mn}$ in the failed cap nuts. High $\mathrm{Cr}$ in carbon steels has been associated with temper embrittlement and low notch toughness. Novel fracture experiments were performed in-situ in an Auger electron spectroscopy system. This technique utilizes liquid N2 assisted fracture in a high vacuum so that fresh fracture surfaces can be analyzed chemically without the usual extrinsic contamination that covers fracture surfaces. The Auger samples displayed brittle mixed IG/cleavage fracture in the new/bad cap nuts and ductile fracture in the old/good cap nuts, consistent with previous observations. In the brittle fracture specimens, Auger electron spectroscopy indicated higher levels of $\mathrm{O}, \mathrm{S}, \mathrm{P}$, and $\mathrm{Ca}$, all of which could contribute to lower toughness in this material. [5]

References:

[1] ASTM F1624, Measurement of Hydrogen Embrittlement Threshold in Steel by Incremental Step Loading Technique. 
[2] ASM Handbook, Vol. 11, 10th Edition, Failure Analysis and Prevention, p. 809.

[3] ASM Handbook, Vol. 13, 10th Edition, Corrosion, p. 329.

[4] K. Farrell, Corrosion 26 (1970) p. 105.

[5] Sandia National Laboratories is a multi-program laboratory managed and operated by Sandia Corporation, a wholly owned subsidiary Lockheed Martin Corporation, for the U.S. Department of Energy's National Nuclear Security Administration under contract DE-AC04-94AL85000.
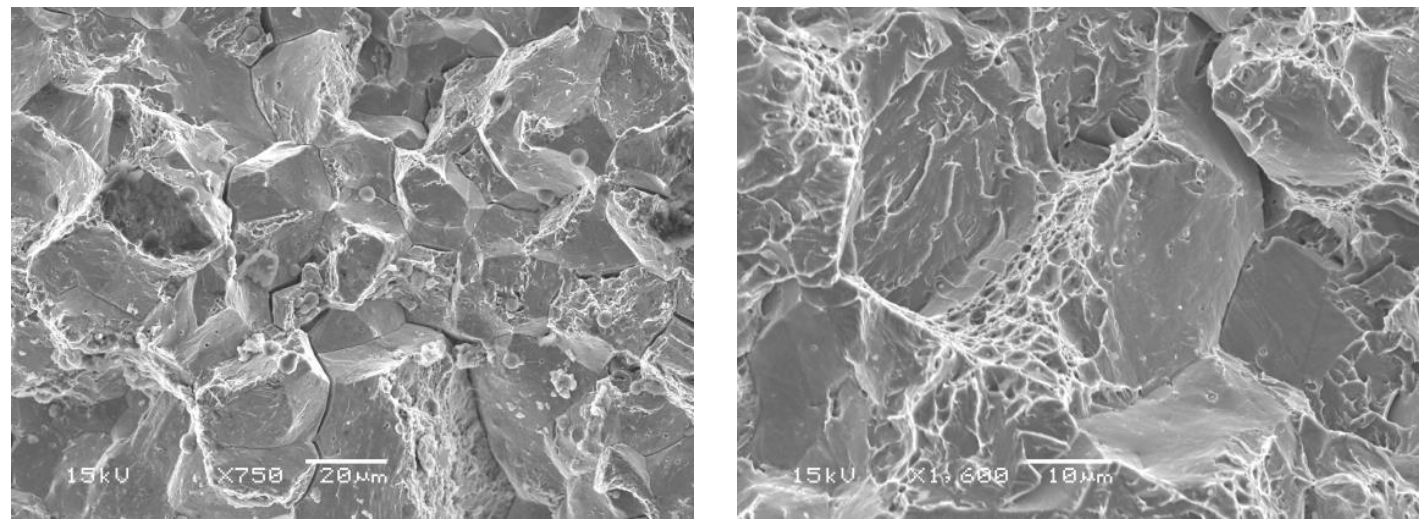

Figure 1. SEM photomicrographs showing brittle intergranular fracture (left) or mixed intergranular, quasi-cleavage, and microvoid coalescence (right).

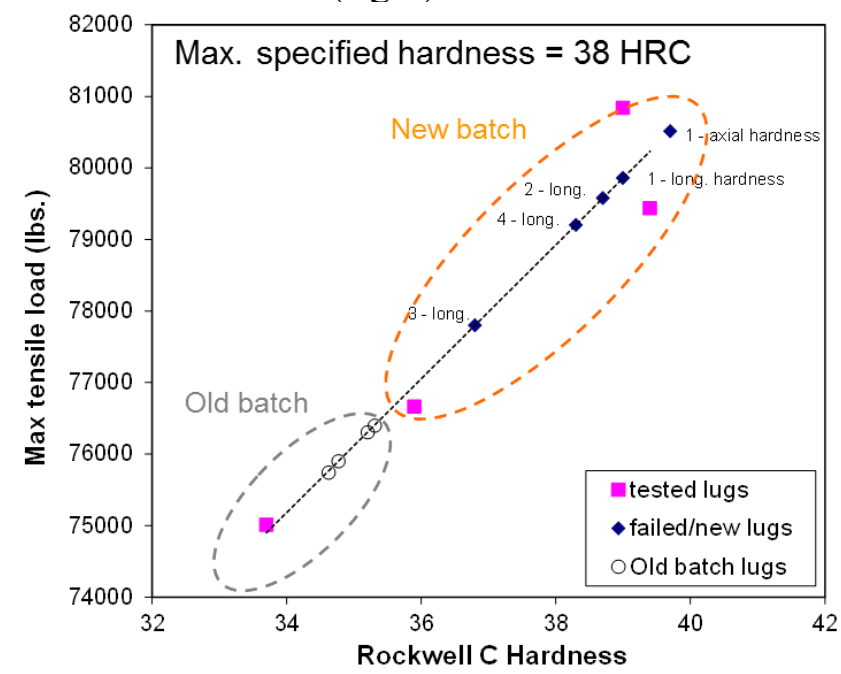

Figure 2. Maximum tensile load vs. Rockwell $\mathrm{C}$ hardness for old lot and new lot cap nuts. In-service failures occurred only in new lots of cap nuts with higher strength and hardness.

Table 1. Chemical analysis results in wt. \% for old (good) and new (bad) lots of cap nuts.

\begin{tabular}{|c|c|c|c|c|c|c|c|c|}
\hline Element & $\mathbf{C}$ & $\mathbf{M n}$ & $\mathbf{P}$ & $\mathbf{S}$ & $\mathbf{B}$ & $\begin{array}{c}\mathbf{H} \\
(\mathrm{ppm})\end{array}$ & $\mathbf{F e}$ & $\mathbf{C r}$ \\
\hline $\begin{array}{c}\text { Old lots } \\
\text { (avg of 2) }\end{array}$ & 0.24 & 1.06 & .015 & .010 & .0012 & 2.5 & 98.5 & - \\
\hline $\begin{array}{c}\text { New lots } \\
\text { (avg. of 4) }\end{array}$ & 0.22 & 0.52 & .025 & .013 & .0008 & 2.3 & 97.7 & $\begin{array}{c}1.5 \\
(\mathrm{EDS})\end{array}$ \\
\hline
\end{tabular}

